image are the same. Symbols of the realm B of the logical necessity which satisfy the condition $\mathrm{V}$, are at the same time images and true images. In other words: a symbol $b_{\lambda}$ is either a true image of $a_{\lambda}$, or it is not a true image; whether it then can still be an image at all, as for instance a false image, - about this we know nothing.

The formulation, "image and true image are identical," is indeed required by the condition $\mathrm{V}$ itself. For we said:

$$
b_{v}=\phi\left[f_{n}\left(a_{\mu}\right)\right]
$$

where it is evident that we must understand by the representation $\phi$ a true image; i. e., if $b_{v}$ might possibly be a false image then it could decidedly not prove that $b_{\mu}$, from which it logically follows, is a true image.

If we now write $\phi_{t}$ for a true representation, then $\mathrm{V}$ will take the form:

$$
\begin{aligned}
\text { if } b_{\nu} & =\phi_{t}\left(a_{\nu}\right) \\
\text { then } b_{\mu} & =\phi_{t}\left(a_{\mu}\right)
\end{aligned}
$$

Thus the truth of $b_{\mu}$ is based, by the fundamental condition $\mathrm{V}$, on the truth of its logically necessary consequence, therefore on the truth of another image, and it would be necessary for us to have previously somehow and from somewhere a true image, then we could by means of $\mathrm{V}$ determine the truth of other images. Still we could not determine the truth of the first image by the condition V. So Hertz forsakes his first point of view, that the images are mere symbols, in themselves neither similar nor different, neither true nor false; and takes his refuge in another criterion of truth, namely experience. "If we have once succeeded in deducing from the collected past experience images of the required quality..." This however means nothing but that the condition $\mathrm{V}$ as criterion of truth has been given up, it was to decide about the truth of the images; instead he appeals to the angesammelte Erfahrung to give us true images and at the same time to guarantee them!

PequakeT, N. H.

KARL SchmidT.

\title{
A MONISTIC CONCEPTION OF LIFE AND LIFE AFTER DEATH.
}

IN REPLY TO JOHAN GUSTAF BJOERKLUND AND HIS EXPOUNDER, MR. J. E. FRIES.

Among the thinkers who have pondered over the problem of the immortality of the soul, Gustaf Björklund is prominent by reason 
of originality and keenness of thought; and yet knowledge of his theory has remained limited to his own country, Sweden. The rest of the world has taken very little notice of his propositions because his books have heretofore remained untranslated. While admitting the significance of Björklund as a thinker I cannot accept his arguments or conclusions, and I will here state briefly the main points which I have to make in comment upon Mr. J. E. Fries's exposition of them in his article "Death and Resurrection" (The Monist, April, I9I0).

First I will briefly point out that my idea of nature is different from Björklund's. The very word "nature" means "growth," and so does its Greek equivalent physis. Growth, development, activity is the most obvious feature which unsophisticated man observed in the world. Yea, the word "world" itself conveys the same idea as the Latin natura, for it is derived from a Saxon root which means "becoming, growing, developing," and which is still preserved in the German werden. Mr. Björklund would exclude from nature its most characteristic feature of self-motion, of producing configurations of higher units, of building up and storing energy as it appears in the vegetation of our globe. The notion that this world consists of inert substance is of very late origin and is due to the analysis made by the chemist who by dissecting life and separating higher units retains its dead elements. By destroying a complex we retain the unrelated parts, and yet the chemist knows very well, or he ought to know, that there is no inert matter. All matter is aglow with a tendency to act, and this tendency does not enter into matter from the outside, but is its inalienable and intrinsic characteristic.

There is no inert matter in the sense that its particles are dead and show symptoms of activity only by a push from the outside. Gravity and all other forces of nature are qualities inherent in matter, and it is not an extraneous energy which pushes the stone toward the ground but it is its own innate life which responds according to given conditions.

It is true, as Mr. Fries says, that I have repeatedly declared that vitality or life force is a quality sui generis. It is an energy of its own and different from all other energies, just as electricity is different from light and from other motion. But Mr. Fries misunderstands my statement if he thinks that according to my view there are two kinds of energy, life energy and physical energy. There is only one energy and this energy appears in different forms, each one being sui generis in the sense that it is different from the 
others, but every one of them can be changed into any of the others according to conditions. Molar motion, or change of place of entire masses, is energy, and molar motion can be changed into heat. Heat is a motion of the very particles of matter among themselves, and it can be changed into ether waves such as light and electricity. A commotion of ether is decidedly different from a commotion of material atoms, and this again from a mere change of place of whole masses. And yet each of these three motions can be transformed into any of the others. Chemical combination is again a kind of energy of its own, though it incidentally may be combined with either or both, heat and electricity, and even molar motion, as e. g., in explosions; yet when we come to a consideration of life forces we find that they are more complicated than all others. Nevertheless they contain all others, and vital functions are sui generis only in so far as they constitute a constant round of continuous functions. Life appropriates foreign materials by assimilation to build up new life according to its kind, and this is called growth. A similar process takes place in inorganic nature, for crystals grow also and assimilate matter to their own form. The most important characteristic of life force, however, is its organization into higher units, a storing up of energy which animal life spends in locomotion. In spite of being a process sui generis it is nothing but a combination of all other kinds of energy. This product of a higher unity contains new features as do all unifications, and the interconnection of the latent life forces, of potential sentiency, produces in animal substance a condition of awareness called feeling, and from feeling the soul develops, with all its wonderful faculties. I can not enter into the details of an explanation of the origin of the soul. I will only insist that the process is as mysterious as other phenomena in the physical, chemical and vegetal domains, but not more so. I claim that there is only one mystery pervading the whole universe and this mystery is existence-the existence of the universe itself. The same mystery confronts us in the formation of a crystal as much as in chemical combinations, in the spontaneity of the falling stone and in the growth of a tree. Everywhere we have self-activity, an inherent faculty of combining into units, or building up structures, or of organizing into higher life units, called organisms, and if we wanted to assume a special outside power to accomplish any one of these functions we would have to assume a specific energy for chemical life, for the growth of crystals, for plant life and the formation of the soul. I grant that the formation of living plasma is a mystery, 
but it would be a greater mystery still if we assumed in addition to the general world mystery a second mystery which comes into the world from the outside.

If we call the domain of physical activity nature or physics I will gladly grant that the domain of organized life constitutes a higher realm, and we may call it supernatural or hyperphysical, but this supernatural life has not, so far as we can see, come from the outside of the world into it, but lies latent in the very constitution of all existence. The hyperphysical grows from the physical, the supernatural develops naturally from the natural, the conditions of the higher lie concealed in the lower forms of cosmic being.

Life is a continuous process and every organism is the link of a long chain. The problem of the origin of life is not yet ripe for solution. Our microscopists have not yet discovered the most primitive life forms, and if they had they would most likely be disappointed to find themselves confronted with a new problem. It is more than probable that there is an intermediate domain between purely chemical processes and organization, and this domain would exhibit activities like that known as fermentation. At any rate we must bear in mind the important role played in organized life by memory. Think of it that the tiniest bacillus has become what it is by the previous activity of its ancestry, and if we want to reproduce it, we would have to repeat in due succession the very same conditions through which it has passed since its differentiation from the most primitive vital function into a definite bacillus. Such is the conclusion which we must accept according to what we know of life. Is it then probable that we shall ever be able to manufacture even the smallest organism?

The formula omne vivum ex vivo must be rendered more exact by restating it thus: Organized life is a continuous process and the nature or quality of every organism is determined by the nature or quality of its ancestors. We may add by way of hypothesis, based on what we know of life, that the nature or quality of every organism consists in the traces of its own activity. Everything that exists (including the tiniest spark of organized life) is acted upon by its surroundings and reacts upon these impressions or impacts received. Life is a function, and its essential characteristic is the constant flux of metabolism in which however the forms of the old traces are preserved. ${ }^{1}$ This is conditioned by the viscosity of living substance which

${ }^{1}$ See "Have Atoms Souls?" Open Court, XXIV, I19-122. For further articles on the soul see bibliography of the author, Philosophy as a Science, p. I75 
renders it very plastic. Every commotion produces a modification of the structure, a vestige, and if the same kind of commotion is repeated the vestige grows stronger and finally develops into an organ. Every organ is the product of its function. Function precedes the formation of organs and is the result of the preservation of a definite and constantly repeated mode of response to a certain kind of stimulus. In the higher sphere of psychic life this preservation of the form of functions is called "memory," and so we may say that every organism is the product of memory. Every bacillus has become what it is by its own doings. Because naturalists have been unable to make organisms we need not jump at the conclusion that organic life has come into the world from the outside, especially as there is no gap between life and inorganic forces, between living substance and so-called inert matter. The transformation of chemical elements into human limbs and brains is an object of common observation.

The significance of Björklund's work consists more in his intentions than in his accomplishments; it lies in his attempt at solving the selfsame problem which plays so prominent a part in religion. "When a man dies shall he live again?" We see that the body decays and nothing is left but ashes. The only answer as to the fate of man is expressed in the Biblical passage, attributed by the author of the third chapter of Genesis to God himself: "For dust thou art and unto dust shalt thou return," and the same truth is most impressively reiterated in Eccl. iii. 19-20. But in spite of everything, man feels instinctively that death does not end all, and he is right. The problem is solved when we understand the part which memory plays in the development of life. Memory builds up organisms. memory shapes our souls, memory makes evolution and progress possible, and memory means immortality. As man does not come from nothing, but is the continuation of his past, so he is not annihilated but his doings and his thoughts, the significance of his life, his soul continues after him. He rests from his labors, but his works follow him. Our life consists of work, and it is in our works that we live on after death.

EDITOR.

\section{MAGIC CIRCLES AND SPHERES.}

Magic circles and spheres have been apparently much less studied than magic squares and cubes. We cannot say that this is because their range of variety and development is limited; but it may 